OPEN ACCESS

Edited by:

Mario Alberto Rodriguez,

Centro de Investigación y de Estudios Avanzados del Instituto Politécnico Nacional (CINVESTAV-IPN), Mexico

Reviewed by:

César López-Camarillo,

Universidad Autónoma de la Ciudad de México, Mexico

Adriane Regina Todeschini, Universidade Federal do Rio de

Janeiro, Brazl

Siddhartha Das,

University of Texas at El Paso,

United States

Humberto Lanz-Mendoza, Instituto Nacional de Salud Pública,

Mexico

*Correspondence:

Serge Ankri

sankri@technion.ac.l

Received: 06 November 2017

Accepted: 16 January 2018

Published: 08 February 2018

Citation:

Nagaraja S and Ankri S (2018)

Utilization of Different Omic

Approaches to Unravel Stress Response Mechanisms in the Parasite

Entamoeba histolytica.

Front. Cell. Infect. Microbiol. 8:19,

doi: 10.3389/fcimb.2018.00019

\section{Utilization of Different Omic Approaches to Unravel Stress Response Mechanisms in the Parasite Entamoeba histolytica}

\author{
Shruti Nagaraja and Serge Ankri* \\ Department of Molecular Microbiology, Ruth and Bruce Rappaport Faculty of Medicine, Technion, Haifa, Israel
}

During its life cycle, the unicellular parasite Entamoeba histolytica is challenged by a wide variety of environmental stresses, such as fluctuation in glucose concentration, changes in gut microbiota composition, and the release of oxidative and nitrosative species from neutrophils and macrophages. The best mode of survival for this parasite is to continuously adapt itself to the dynamic environment of the host. Our ability to study the stress-induced responses and adaptive mechanisms of this parasite has been transformed through the development of genomics, proteomics or metabolomics (omics sciences). These studies provide insights into different facets of the parasite's behavior in the host. However, there is a dire need for multi-omics data integration to better understand its pathogenic nature, ultimately paving the way to identify new chemotherapeutic targets against amebiasis. This review provides an integration of the most relevant omics information on the mechanisms that are used by E. histolytica to resist environmental stresses.

Keywords: Entamoeba histolytica, omics, oxidative stress, nitrosative stress, iron starvation, glucose starvation, microbiota, virulence

\section{INTRODUCTION}

Amebiasis, caused by the eukaryotic parasite Entamoeba histolytica, is an enormous global medical problem that still exists due to poor sanitary and unhygienic conditions. According to the World Health Organization, 50 million people in India, Southeast Asia, Africa, and Latin America suffer from amebic dysentery and liver abscesses, and amebiasis causes the death of at least 100,000 individuals each year. In $90 \%$ of the infected patients, E. histolytica trophozoites normally inhabit the colon and spend their time in the host as a non-pathogenic commensal. However, the reasons why these trophozoites become virulent and invasive are unknown. Anti-amoebic drugs are the preferred choice due to the unavailability of vaccines. Based on their site of action, two categories of anti-amoebic drugs are used, namely, luminal amebicides (diloxanide furoate, and Iodoquinol) (Marie and Petri, 2013) and tissue amebicides (metronidazole) (Salles et al., 2007; Tazreiter et al., 2008; Marie and Petri, 2013) and potential resistance of the parasite to metronidazole is a real concern. Moreover, metronidazole is not effective in eliminating cysts inside the lumen and thus a combination of luminal and tissue amebicides is generally recommended (Marie and Petri, 2013). Recently, auranofin has been identified as a potent drug that targets redox enzymes in 
the parasite, eventually leading to oxidative stress in the parasite and it has found to be more effective than metronidazole (Debnath et al., 2012). Nevertheless, it is still a need of the hour to identify more potential drug targets to treat amebiasis. E. histolytica is challenged in the host environment due to fluctuations in partial pressure of oxygen, changes in glucose concentration and changes in the composition of the microbiota. The activation of innate immune responses against the parasite leads to the production of reactive oxygen species (ROS), nitric oxide (NO) by macrophages, complement activation and phagocytosis, and heat shock responses (Mortimer and Chadee, 2010; Moonah et al., 2013; Nakada-Tsukui and Nozaki, 2016; Olivos-Garcia et al., 2016). The parasite must be capable of adapting to the demand of surrounding environment in order to survive. This adaptive response of the parasite provides a shield against the host response as well as aids in their survival (Figure 1). In eukaryotic cells, the general stress response mechanism is a tightly orchestrated process. The first step involves the role of a stress-sensor proteins (heat shock proteins, nutrient sensing proteins, antioxidant proteins and also chromatin-proteins) to relay the message to the cells to adapt to stress (De Nadal et al., 2011; Walter and Ron, 2011; Santi-Rocca et al., 2012; Smith and Workman, 2012; Shahi et al., 2016a; Figure 2). The transfer of this stress signal to downstream proteins leads to a signal transduction cascade. This cascade begins with the phosphorylation of effector proteins [eIF2 kinases and Mitogen Activating Protein Kinases (MAPK)], and these proteins are known to play a role during stress. This eventually helps the cells to adapt to the stress by either attenuating translation (by phosphorylation of serine residue of the $\alpha$ subunit of eIF2 leading to its inactivation) (Jiang and Wek, 2005; Hendrick et al., 2016; Sharma et al., 2016) or through the

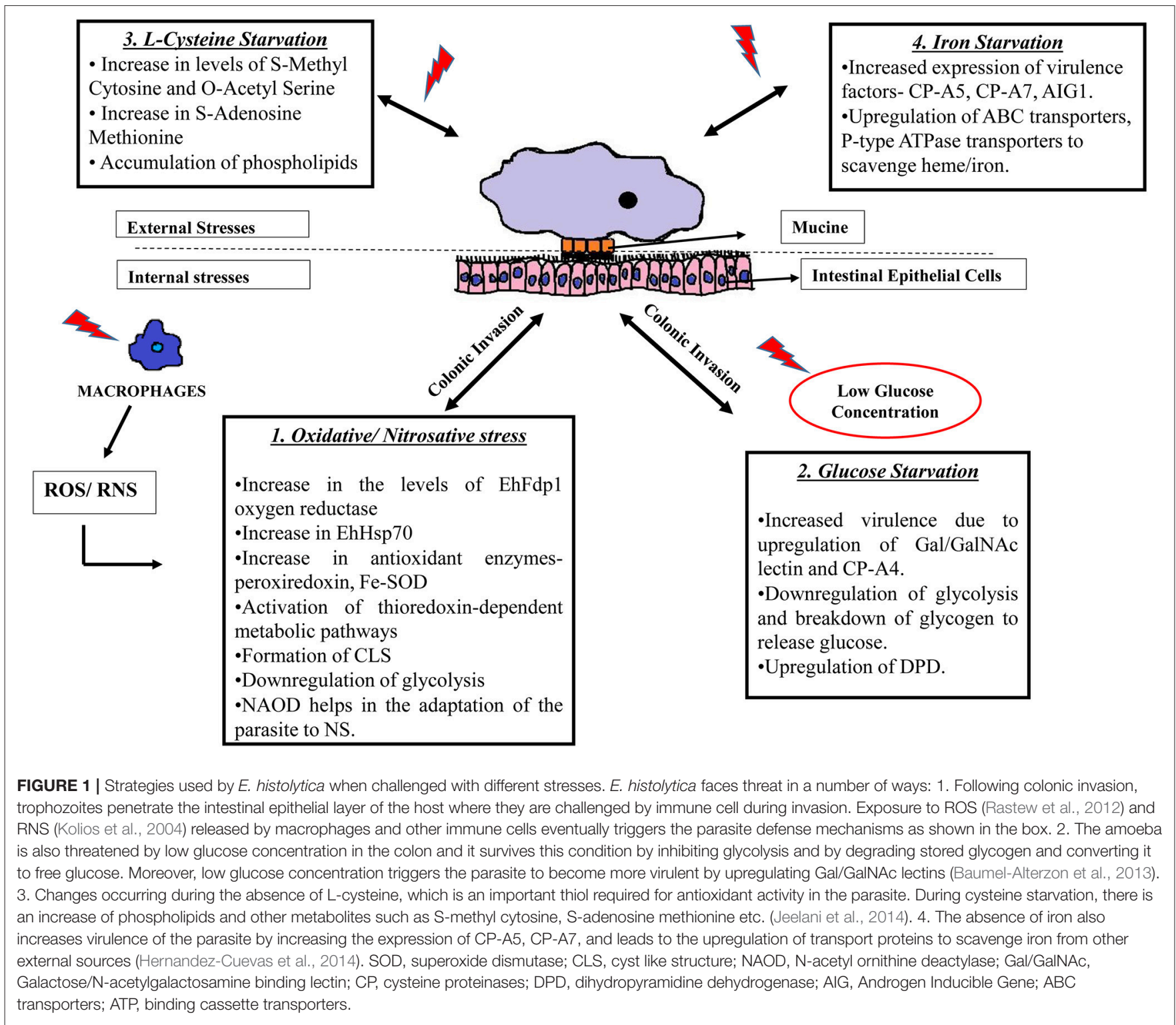




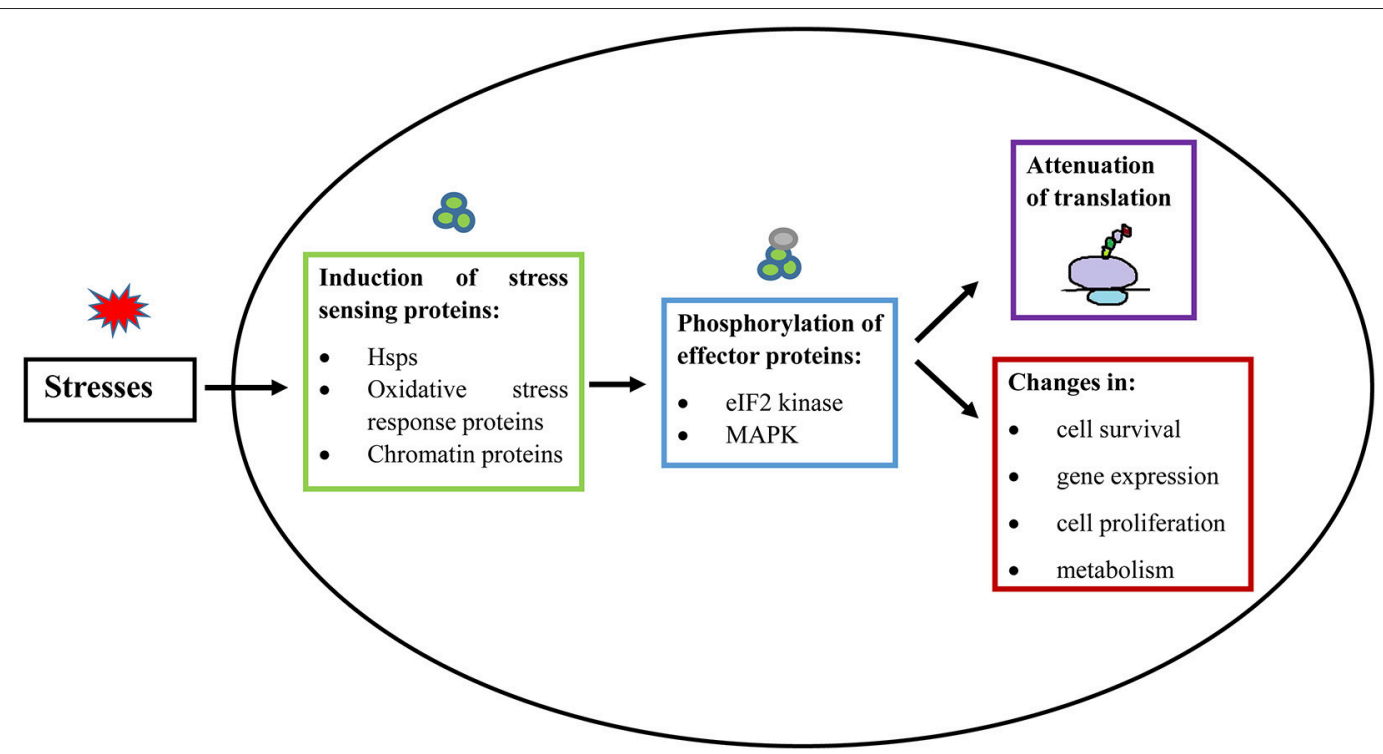

FIGURE 2 | General principle of stress response in eukaryotic cells and E. histolytica. When a cell is exposed to stress, there is an activation of a stress-responsive protein (De Nadal et al., 2011; Walter and Ron, 2011; Smith and Workman, 2012), which induces signal transduction mediated by protein phosphorylation (Darling and Cook, 2014; Sharma et al., 2016). The stress signal is then transferred to downstream effector proteins. These stress responses generally lead to inhibition of cap-dependent translation initiation and consequent suppression of general protein synthesis. Stress responses also lead to additional changes, involving modulation of gene expression, cell proliferation, cell survival, and changes in metabolism (Lopez-Maury et al., 2008). Hsps, Heat shock proteins; elF2, Eukaryotic Intitation Factor 2; MAPK, Mitogen Activated Protein Kinases.

modulation of gene expression and metabolism (Vonlaufen et al., 2008; Darling and Cook, 2014). While conventional molecular techniques provided an outline, the gradual development and utilization of "omics" technologies and bioinformatics to study E. histolytica open new avenues to understand the complexity of its behavior under different conditions. For example, the field of DNA microarrays and proteomics have revolutionized our manner to assess the virulence of the parasite and its ability to cope with various stresses (Gilchrist et al., 2006, 2010; López-Camarillo et al., 2009), study the expression of different genes in the parasite exposed to UV radiation (Gilchrist et al., 2006; Weber et al., 2009), and assess the effects of metronidazole as a chemotherapeutic agent (Tazreiter et al., 2008). Moreover, there are other studies investigating the proteome of cell surface proteins and the excretory-secretory protein system of the parasite that may help in understanding its pathogenicity (Biller et al., 2014; Ujang et al., 2016).With the help of different (transcriptomic, genomic, and metabolomics) omics analysis, it has now become possible to study the responses of the parasite to various stresses during host invasion and these studies can provide several critical pieces of evidence as to how the parasite manages to survive inside the host (Table 1). Thus, it is essential to review all the data in order to characterize the mechanisms essential for stress response and identify potential drug targets against this parasite. This article presents an overview of recent advances that have been made by using various omics approaches to investigate stress response in E. histolytica, with focus on oxidative stress (OS) and nitrosative stress (NS).

\section{OXIDATIVE STRESS - WHAT TRIGGERS IT?}

The key players that are involved in OS are a variety of ROS. They are capable of damaging essential biomolecules in the cell such as DNA, proteins, lipids and they lead to the fragmentation of the endoplasmic reticulum (ER) due to the accumulation of misfolded proteins (Imlay, 2003; Apel and Hirt, 2004; Pineda and Perdomo, 2017). In the large intestine, the invading E. histolytica trophozoites encounter OS. The sources of these stresses are fluctuations in oxygen tension in the intestinal lumen and the generation of ROS by cells of the immune system. Hydrogen peroxide $\left(\mathrm{H}_{2} \mathrm{O}_{2}\right)$ is capable of damaging the proteins by its interaction with thiol groups, which are present in the cysteine side chains as well as with metal cofactors. Once formed, ROS leads to the oxidative damage of proteins thereby affecting their structure and functional properties (Shacter, 2000; Wu et al., 2006; Aiken et al., 2011). OS resistance contributes to the pathogenic potential of E. histolytica (Rastew et al., 2012).

\section{How Did Omics Help Us Understand Oxidative Stress Response in E. histolytica?}

Analysis of the parasite's transcriptome in response to OS showed that this parasite copes with this stress by a complex modulation of a broad set of genes encoding proteins that are mainly involved in protein folding [Heat shock proteins (Hsps)], amino acid catabolism (MGL-1), signaling/regulatory pathways, and also in pathways involved in repair during DNA damage 
TABLE 1 | A list of the different omics approaches used to analyze stress responses in E. histolytica.

\begin{tabular}{|c|c|c|c|}
\hline References & Omics approach used & Type of stress & Summary of the study \\
\hline Vicente et al., 2009 & Transcriptomics & Oxidative stress & $\begin{array}{l}\text { - Upregulation of Hsps, MGL-1, DNA repair proteins } \\
\text { - Increase in the expression of signaling and regulatory proteins } \\
\text { - Upregulation of Fe-S flavoproteins }\end{array}$ \\
\hline Jeelani et al., 2014 & Metabolomics & Oxidative stress & $\begin{array}{l}\text { - Increased glycerol-3-phosphate levels } \\
\text { - Upregulation of components of chitin biosynthesis pathway } \\
\text { - Inactivation of key glycolytic enzymes }\end{array}$ \\
\hline Davis et al., 2006 & Comparative proteomics & Oxidative stress & $\begin{array}{l}\text { - Rahman strain deficient in peroxiredoxin and superoxide dismutase } \\
\text { compared to the HM1:IMSS strain }\end{array}$ \\
\hline Vicente et al., 2009 & Transcriptomics & Nitrosative stress & $\begin{array}{l}\text { - Increase in expression of DNA damage repair proteins } \\
\text { - Upregulation of Hsps, MGL-1 } \\
\text { - Upregulation of phospholipid-Transporting-P-type ATPase } \\
\text { - Upregulation of signaling and regulatory proteins }\end{array}$ \\
\hline Hertz et al., 2014a,b & Proteomics & Nitrosative stress & - S-nitrosylation of cysteine residue of heavy subunit of Gal/GalNAc Lectin \\
\hline Santi-Rocca et al., 2012 & Proteomics & Nitrosative stress & $\begin{array}{l}\text { - Inactivation of glycolytic enzymes } \\
\text { - Low levels of ATP } \\
\text { - Fragmentation of ER }\end{array}$ \\
\hline Tovy et al., 2011 & Proteomics & Glucose Starvation & $\begin{array}{l}\text { - Upregulation of Gal/GalNAc lectin } \\
\text { - Upregulation of DPD }\end{array}$ \\
\hline Baumel-Alterzon et al., 2013 & Transcriptomics & Glucose starvation & $\begin{array}{l}\text { - Upregulation of DPD, MGL-1 } \\
\text { - Upregulation of virulence factors such as Gal/GalNAc lectins } \\
\text { - Downregulation of glycolytic genes }\end{array}$ \\
\hline Husain et al., 2011 & Transcriptomics & Cysteine Starvation & $\begin{array}{l}\text { - Upregulation of Fe-S family of proteins } \\
\text { - Accumulation of phosphatidylisopropanolamine }\end{array}$ \\
\hline Husain et al., 2010 & Metabolomics & Cysteine Starvation & $\begin{array}{l}\text { - Accumulation of S-methyl cysteine } \\
\text { - Upregulation of metabolites }\end{array}$ \\
\hline Hernandez-Cuevas et al., 2014 & Transcriptomics & Iron Starvation & $\begin{array}{l}\text { - Upregulation of cysteine proteinases, ribosomal proteins, elongation factors } \\
\text { - Upregulation of AlG1 } \\
\text { - Upregulation of } \mathrm{NADH} \text {-dependent oxidoreductases, transport proteins }\end{array}$ \\
\hline Weber et al., 2006 & Transcriptomics & Heat Shock & $\begin{array}{l}\text { - Upregulation of Hsp70, CP-4, CP-6 } \\
\text { - Differential allelic expression of Gal/GalNAc lectin }\end{array}$ \\
\hline Weber et al., 2009 & Transcriptomics & UV irradiation & - Upregulation of Fe-S proteins and DNA repair protein \\
\hline
\end{tabular}

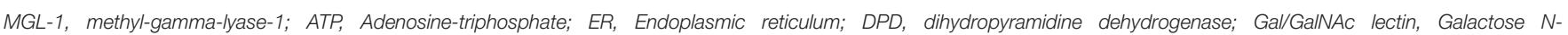
acetylgalactosamine lectin; AIG-1, Androgen Inducible gene; Fe-S, Iron sulfur cluster proteins.

and metabolism (Vicente et al., 2009). The authors reported an upregulation of $\operatorname{Rad} 3$ helicase, Rad50, and DNA excision base repair proteins. These proteins along with Rad52, are also involved in DNA damage response in the parasite during UV irradiation (Weber et al., 2009) Table 1. Two genes coding for deoxyuridine triphosphate nucletotidehydrolase (dUTPase) were upregulated in the parasite exposed to OS. These genes are considered essential for the stability of DNA and have been proposed as a potential drug target against parasites (Nguyen et al., 2005). A 4-fold increase in the homolog of polynucleotide kinase-3 phosphatase along with a 2-fold increase in MutS DNA repair proteins was also reported. These proteins are known for their role in repairing DNA breaks during formed during OS (Chang et al., 2002; Blondal et al., 2005). These proteins were also found to be upregulated when the parasite was exposed to NS.

A functional study of genes responsive to OS revealed the role of the stress-induced adhesion factor, the phospholipidtransporting P-type ATPase and the EhFdp1 oxygen reductase in the resistance of the parasite to OS (Rastew et al., 2012).

The role of Hsps in the resistance of the parasite to stresses has been widely credited as they facilitate the stabilization/sequestration of damaged or misfolded proteins (Kaul and Thippeswamy, 2011). Hsps are very well conserved in all organisms and they function as molecular chaperons during 
any stressful event (Perez-Morales and Espinoza, 2015). Hsp70 is known to aid in the refolding of denatured and misfolded proteins, and translocation of secretory proteins (Voisine et al., 1999). E. histolytica Hsp70 (EhHsp70) is essential for the resistance of the parasite to OS, the formation of liver abscess, and its levels are also upregulated during heat shock response in the parasite (Akbar et al., 2004; Weber et al., 2006; Santos et al., 2015) Table 1. EhHsp70 expression is also upregulated when the E. histolytica Dnmt2 homolog (Ehmeth) is overexpressed. Ehmeth catalyzes the methylation of $\mathrm{C}_{38}$ present in the anticodon loop of tRNA ${ }^{\text {Asp }}$ (Tovy et al., 2010). Ehmeth-overexpressing trophozoites exhibit significantly greater survivability to $\mathrm{H}_{2} \mathrm{O}_{2}$ exposure, which emphasizes the role of EhHsp70 in OS resistance suggesting that EhHsp70 expression is under epigenetic control (Fisher et al., 2006).

It has been recently reported that the gene expression under OS influence is regulated by a transcription factor that binds to a specific motif (AAACCTCAATGAAGA) in the promoters of the genes receptive to $\mathrm{H}_{2} \mathrm{O}_{2}$ (Pearson et al., 2013). It is interesting to note that there is an association between the expression of E. histolytica OS responsive genes and the parasite's virulence (Rastew et al., 2012). Antioxidant enzymes such as glutathione peroxidase, glutathione, and catalase provide a shield for an organism to defend the harsh conditions of OS. E. histolytica lacks the presence of these antioxidative enzymes (Tekwani and Mehlotra, 1999) and it relies mostly on two proteins for its defense against OS. These are the $29-\mathrm{kDa}$ peroxiredoxin (Sen et al., 2007) and the iron peroxide dismutase (Fe-SOD) (Bruchhaus and Tannich, 1994). E. histolytica also relies on exclusive variants of antioxidants that have a low molecular mass like cysteine (Krauth-Siegel and Leroux, 2012). In contrast to E. histolytica, which utilizes superoxide dismutases (SOD), Giardia intestinalis-another common intestinal parasite, has also developed defense mechanisms to cope with OS. This parasite utilizes superoxide reductases (SORs) for the elimination of superoxide anions by reducing $\mathrm{H}_{2} \mathrm{O}_{2}$ (Testa et al., 2011). Moreover, this parasite contains high levels of NADH-dependent oxidase for detoxification of oxygen (Tekwani and Mehlotra, 1999). Pyruvate has also been identified as another alternate potential antioxidant protein that detoxifies $\mathrm{H}_{2} \mathrm{O}_{2}$ inside Giardia spp (Biagini et al., 2001).

An interesting study using capillary electrophoresis-mass spectrometry was performed to determine the effects of OS on the metabolism of the parasite (Husain et al., 2012). OS inactivates the glycolytic pathway and increases the production of glycerol along with changes in nucleotide metabolism, and activation of the chitin biosynthetic pathway. These data suggest that the glycerol synthesis pathway defends the parasite against OS and that oxidized proteins may be crucial constituents of the parasite's machinery to cope with OS. E. histolytica accounts on the thiol-dependent redox metabolism to resist OS (recently reviewed in Jeelani and Nozaki, 2016). The thioredoxindependent system has been extensively studied in E. histolytica and it consists of Fe-superoxide dismutase, rubrerythrin, peroxiredoxin, flavodiiron proteins, and amino acids including L-cysteine, and thioprolines (thiazolidine-4-carboxylic acids), and S-methyl-l-cysteine respectively (Jeelani and Nozaki, 2016). Some of the thiol-dependent redox metabolism proteins like the iron-containing superoxide dismutase have been found to be oxidized in trophozoites exposed to $\mathrm{H}_{2} \mathrm{O}_{2}$ (Shahi et al., 2016a). It was also reported that the presence of superoxide radical anions, which cause OS, lead to the expression of superoxide dismutase and these enzymes are known to contain iron (Bruchhaus and Tannich, 1994). These enzymes further interact with the metabolites of the drug metronidazole and form covalent adducts (Leitsch et al., 2007). The effect of oxidation on the activity of the amebic iron-containing superoxide dismutase has still not been determined yet. Proteomics has helped us to strengthen our understanding of the parasite's response to OS. Comparative proteomics of the virulent strain-HM1:IMSS and the avirulent strain-Rahman showed that Rahman is deficient in two proteins with antioxidative properties (peroxiredoxin and superoxide dismutase). Overexpression of peroxiredoxin in Rahman restores its resistance to OS and its ability to cause colitis in human colonic xenografts (Davis et al., 2006). Proteomics has also been extensively used to study the composition of cysts (Ali et al., 2012) and cyst-like structures (CLS) (LunaNacar et al., 2016). CLS is formed in response to OS in the parasite, and they may be part of the parasite's mechanisms to stand OS. CLS share features found in cysts like the presence of a chitin-like resistant coat on their surface and features of trophozoites exposed to OS like the expression of stress response proteins and redox homeostasis (Rastew et al., 2012) and a downregulation of glycolysis and metabolism-related proteins (Jeelani and Nozaki, 2016). Surprisingly, there is no proteomics data available in the literature about the parasite's response to OS and we are currently working to fill this knowledge gap. However, redox proteomics has been recently performed by using resin-assisted capture of oxidized proteins (OX-RAC) (Shahi et al., 2016a). OX-RAC does not provide information about the differential level of proteins before, and after exposure to OS, however, it somewhat identifies oxidized cysteines in proteins following the exposure of the parasite exposed to OS (Kohr et al., 2011). Some of the oxidized proteins identified by OX-RAC like superoxide dismutase have been associated with antioxidant activity. However, a very weak overlapping was found between genes that have their expression changed during OS (Vicente et al., 2009) and oxidized proteins identified by OX-RAC (Shahi et al., 2016a).

Taken together, these findings emphasize the importance of performing multi-omics approaches to fully understand the response of the parasite exposed to stress.

\section{NITROSATIVE STRESS-HOW DOES THE PARASITE COPE WITH IT?}

A second challenge encountered by E. histolytica presents itself in the form of reactive nitrogen species (RNS) in the large intestine. Here the parasite is exposed to $\mathrm{NO}$ at nanomolar concentrations by the cells of intestinal epithelium (Kolios et al., 2004). During acute inflammation, the activation of specific 
immune cells of the host's immune system comprising of natural killer cells, macrophages, and neutrophils releases NO in micromolar amount (Thomas et al., 2008; Begum et al., 2015). $\mathrm{S}$-nitrosylation is a post-translational modification that occurs by covalent attachment of $\mathrm{NO}$ group to the thiol side chain of cysteine residues in proteins (Hess et al., 2005). NO-mediated cytotoxicity is partly due to the formation of S-nitrosylated proteins which results in aberrant protein function. For example, the inactivation of key glycolytic enzymes in the parasite exposed to NO leads to the fragmentation of the endoplasmic reticulum, low levels of ATP and the death of the parasite (Santi-Rocca et al., 2012). S-nitrosylation of E. histolytica cysteine proteinases, which are essential virulence factors, inactivate their activity (Siman-Tov and Ankri, 2003). S-nitrosylated (SNO) proteins may also be involved in the regulation of protein activity and function (Gould et al., 2013). Insights into the formation of SNO proteins and their regulation can be achieved by performing SNO-RAC analysis. This technique involves the capture of SNO proteins by chromatography on thiopropyl sepharose and mass spectrometry for their identification (Forrester et al., 2009). The heavy subunit of the E. histolytica Gal/GalNAc lectins was one of the SNO proteins identified by SNO RAC (Hertz et al., 2014a). S-nitrosylation occurred in the cysteine residues of the Gal/GalNAc lectin-carbohydrate recognition domain, which in turn disabled E. histolytica to attach to mammalian cells (Hertz et al., 2014a). The effects of NO on E. histolytica were also studied by transcriptomics. The most extensive groups of genes induced by NS are those related with signaling/regulatory processes, DNA repair, redox-regulation, glycolysis-related genes, and lipids (Vicente et al., 2009; Santi-Rocca et al., 2012). There is a significant overlap of genes modulated under NS and OS including genes involved in degradation and repair of misfolded proteins, lipid metabolism, transport and glycosylation, and DNA repair (Vicente et al., 2009). This overlap shows that the parasite uses common strategies to overcome the cytotoxicity of ROS and NOS (Vicente et al., 2009). Functional studies have demonstrated that Ehmeth is involved in the resistance of $E$. histolytica to NS (Hertz et al., 2014b). The authors proposed that enolase, a glycolytic protein that inhibits Ehmeth activity (Tovy et al., 2010), cannot bind to SNO-Ehmeth, thereby leading to higher $\mathrm{RNAA}^{\text {Asp }}$ methylation. NO resistance can also be achieved by the methylation of tRNA ${ }^{\text {Asp }}$ (Hertz et al., 2014b) and this requires more studies to elucidate the mechanism.

Infection with $E$. histolytica leads to non-symptomatic amoebiasis in $90 \%$ of the cases (Nath et al., 2015; Ishikane et al., 2016). Despite the absence of apparent inflammation, the parasite is nevertheless exposed to nanomolar levels of $\mathrm{NO}$ (Kolios et al., 2004). The exposure to low NO concentration can also occur due to molecules produced during the mechanism of denitrification by the microbiome present in the gut (Vermeiren et al., 2009). This non-toxic concentration of NO may prepare the parasite to resist higher concentration of NO. A recent study (Shahi et al., 2016b) has tested this hypothesis by adapting E. histolytica to a progressive amount of the NO donor Snitrosoglutathione (GSNO) up to $120 \mu \mathrm{M}$. Here, the authors identified and studied the role of $\mathrm{N}$-acetyl-ornithine deacetylase (NAOD) in aiding the parasite to adapt to NS. NAOD catalyzes the deacetylation of $\mathrm{N}$-acetyl-L-ornithine to acetate and ornithine respectively. However, they found that the catalytic activity of this enzyme is not necessary to confer this protective effect on the parasite. Rather, NAOD has an interacting partner; glyceraldehyde 3-phosphate dehydrogenase (GAPDH). GAPDH has many roles apart from its role in metabolism (Nicholls et al., 2012). Its expression is increased in trophozoites exposed to NS and a high expression of this enzyme is detrimental to the parasite (Shahi et al., 2016b). Consequently, NAOD serves as a moonlighting protein that neutralizes the detrimental effect of GAPDH and helps the parasite to adapt to NS. Exciting pieces of evidence about the adaptation of the parasite to NS stem from SNO-RAC analysis (Trebicz-Geffen et al., 2017). Out of the SNO proteins in trophozoites adapted to NS, a significant enrichment of actin family cytoskeleton proteins was found. Trophozoites adapted to NO have their ability to form actin filaments impaired and consequently have their virulence reduced. These phenotypes are reversed upon removal of GSNO from the medium which suggests that the parasite has to compromise on some level for its adaptation to NS.

While E. histolytica depends on the NAOD-GAPDH interaction to neutralize the toxic effects NO, flavohemoglobin (flavoHb) in Giardia intestinalis reported to aerobically metabolize NO efficiently (Rafferty and Dayer, 2015). During NS, the expression of this protein is increased, and hence it aids in the breakdown of $\mathrm{NO}$, whereas under normal conditions its expression is low.

\section{GLOBAL CHANGES IN THE PARASITE IN THE ABSENCE OF L-CYSTEINE, IRON, AND GLUCOSE}

\section{L-Cysteine Starvation}

The parasite requires L-cysteine for its growth and survival. It obtains L-cysteine either through the extracellular medium or produces it via the de novo synthesis pathway with the help of Serine acetyl transferase (SAT) and cysteine synthase (CS) (Pye et al., 2004; Hussain et al., 2009). It is well known that cysteine takes part into the post-translational modifications of several proteins and its role also extends to redox mechanisms, electron transfer reactions, and many more processes (Beinert et al., 1997). The unique feature of this amino acid lies in the ability of its thiol group to endure redox reactions owing to its antioxidant property (Krauth-Siegel and Leroux, 2012). This feature makes cysteine extremely beneficial for the parasite which is deficient of antioxidant enzymes such as catalase and glutathione S-transferases. Cysteine is also essential for its growth, its adherence, and its resistance to OS (Jeelani et al., 2014) and also protects the parasite from the oxidative stress induced by the anti-amebic drug metronidazole (Leitsch et al., 2007). During the course of NS, the requirement of L-cysteine is increased, and the de novo pathway tries to compensate for increasing the production of cysteine. Yet, the amount of cysteine remains low in the cell and requires the addition of L-cysteine in the medium (Jeelani and Nozaki, 2014). Transcriptome analysis performed in the absence of L-cysteine revealed the upregulation of several genes belonging to the Fe-S cluster 
family of proteins. Among them, three iron-sulfur flavoproteins (EHI_025710, EHI_067720, and EHI_138480) showed higher expression in the absence of L-cysteine. Downregulation of EHI_025710 expression severely affected the growth of the parasite, whereas the downregulation of EHI_138480 showed a mild defect in the growth of E. histolytica in the absence of cysteine (Husain et al., 2011).

The deprivation of cysteine has also led to an increase in the intracellular concentration of metabolites such as $\mathrm{O}$-acetyl serine sulfhydralase, glycerol-3-phosphate, and isopropanolamine (Table 1). Moreover, S-methyl cytosine levels were also increased in the cysteine-starved trophozoites, whereas under normal growth condition, S-methyl cytosine was undetectable (Husain et al., 2010). Cysteine deprivation has also caused an accumulation of phosphatidylisopropanolamine (Husain et al., 2011). The role of this unusual phospholipid is still unknown.

\section{Iron Starvation}

Iron is essential for the growth of E. histolytica (Park et al., 2001). Ferric ammonium citrate is provided to the parasite as the source of iron in the medium under laboratory conditions. In the host, the trophozoites scavenge iron from the bacterial flora and the iron-binding proteins of the host such as hemoglobin and ferratin by either phagocytosis or through hemophores or siderophores (Wandersman and Delepelaire, 2004). These proteins are released once the trophozoites phagocytose the cells (Lopez-Soto et al., 2009). Not much is known about the uptake, storage, and utilization of iron in E. histolytica. However, only a few proteins such as Rubrerythrin, NifS, and NifU are known to be involved in the iron-sulfur cluster formation (Ali et al., 2004; Maralikova et al., 2010). Iron is essential for the activity of proteins such as alcohol dehydrogenase 2, superoxide dismutase and ferredoxin (Tannich et al., 1991). Exposure to low iron concentrations in vitro impairs the parasite's adherence and cytopathic activity (Lee et al., 2008; Espinosa et al., 2009) suggesting the central role of iron toward the pathogenicity of the parasite. Iron may also affect the attachment of the parasite to the host cells along with cytotoxicity. Interestingly, there is a definite correlation between adherence, cytopathic activity and increasing concentration of iron. This effect is solely specific to iron and replacing the iron with other cationic salts did not reproduce this result (Lee et al., 2008). Transcriptome analysis of trophozoites growing in the absence of iron shows an increase in the transcription level of cysteine proteinases (CP-A5, CP-A7, and CP-EHI_01850), ribosomal proteins and elongation factors which are required for translation (Table 1). Iron deprivation also upregulates the expression of acyl-CoA synthetase, Androgen-Inducible Gene 1 (AIG1), ComEC protein, NADPH-dependent oxidoreductase $\left(\mathrm{EhNO}_{2}\right)(\mathrm{Hernandez}-\mathrm{Cu}$ evas et al., 2014). The authors have also reported the higher expression of three genes belonging to the AIG1 family (EHI_022500, EHI_115160, and EHI_195260). A comparative study between two Entamoeba histolytica cell lines showed that these AIG1 genes were highly expressed in one of the cell lines that caused liver abscess in the gerbil model compared to the other which did not produce abscess (Biller et al., 2010). This observation suggests that AIG1 has a role in the virulence of the parasite. EhNO $\mathrm{EN}_{2}$ is involved in reducing cystine to cysteine as cysteine is normally present in the oxidized state inside the cells. Thus, its reduction is necessary before its utilization for various functions. $\mathrm{EhNO}_{2}$ also takes part in the reduction of metronidazole to activate this drug to produce reactive species that are toxic to the parasite (Jeelani et al., 2010). Three families of transporters were also upregulated in the absence of iron. ABC-family of transport proteins, P-glycoprotein-5 and Major family transporters (Hernandez-Cuevas et al., 2014). A similar family of transporters present in Leishmania is known for its ability to scavenge heme/iron from the medium (PerezVictoria et al., 2001). An increase in the expression of these transporters in E. histolytica suggests that the parasite tries to acquire iron/heme from different sources during iron starvation. However, the role of these transporters in E. histolytica needs to be determined.

\section{Glucose Starvation}

E. histolytica resides the human colon, a niche where the amount of available glucose for fermentation is low (around 0.2 gr glucose $/ \mathrm{kg}-1$ tissue) due to the high absorptive capacity of the glucose transporters in the small intestine (Cummings and Macfarlane, 1997; Kellett et al., 2008; Hirayama et al., 2009). As a result, the parasite is facing glucose starvation (GS) in the human gut. The phenotypic and metabolic responses of E. histolytica to GS have been recently reviewed (BaumelAlterzon and Ankri, 2014). When exposed to GS, the parasite downregulates the expression of genes involved in glycolysis and upregulates the genes involved in the degradation of stored products such as glycogen granules to make free glucose (Table 1). The research of new sources of energy by the parasite is illustrated by the upregulation of dihydropyrimidine dehydrogenase (DPD) expression. DPD is involved in the degradation of pyrimidines, and it is essential for the adaptation of E. histolytica to GS (Baumel-Alterzon et al., 2013). Although the exact role of DPD in the adaptation of E. histolytica to GS is still not understood, it is possible that the induction of DPD expression during glucose starvation contributes to energy production through the degradation of pyrimidines (Girjes et al., 1995; Beaulande et al., 1998). Metabolomics approaches that have been recently adapted to the study of E. histolytica metabolism (Jeelani and Nozaki, 2014) will help establish the existence of these pyrimidine degradation pathways in E. histolytica. Another example that illustrates the ability of the parasite to seek for an alternative source of carbon is the $\beta$-amylase-mediated degradation of mucin present in the colon (Thibeaux et al., 2013).

Another behavior associated with the exposure of the parasite to GS is its enhanced virulence. This phenotype correlates with the upregulation of some virulence factors like the Gal/GalNAc lectins and EhCP-A4, which is a cysteine protease that aids the parasite to invade the host by destroying the intracellular matrix (Baumel-Alterzon et al., 2013).

GS is also involved in epigenetic regulation by promoting the shuttling of the glycolytic enzyme enolase in the nucleus and the inhibition of Ehmeth (Tovy et al., 2011). The consequence of Ehmeth inhibition on the adaption of the parasite to GS is not yet understood. 


\section{HUMAN INTESTINAL GUT FLORA}

The gut hosts a plethora of microbes, and their number exceeds $10^{14}$ (Thursby and Juge, 2017). It is estimated that about 400-1,000 bacterial species are present in the intestine, and $97 \%$ of the total population is made up by $30-40$ species of bacteria (Xu et al., 2003; Sonnenburg et al., 2004; Jandhyala et al., 2015). The heterogeneous population of microbes inside the human gastrointestinal (GI) tract gives them the potential to influence human physiology in terms of promoting health and causing a wide variety of diseases such as obesity, irritable bowel syndrome and diarrhea, cardiovascular disorders, liver cirrhosis, to name a few (Chang and Lin, 2016). Upon entry into the host, E. histolytica finds itself in contact with a plethora of bacterial species. The intestinal lumen is the site of proliferation of the E. histolytica trophozoites, and they phagocytose the resident bacteria. Bacteria possessing specific recognition motifs were able to adhere to the parasite and to undergo ingestion (Bracha and Mirelman, 1984). The intricate relationship that exists between E. histolytica and the gut flora was the subject of many studies which concluded that it affects greatly several aspects of E. histolytica physiology. An axenic culture of E. histolytica replenished with E. coli O:55, was found to be more virulent or less virulent compared to the axenic culture alone depending on the time of interaction between the parasite and E. coli O:55 (Bracha et al., 1982; Mirelman, 1987; Padilla-Vaca et al., 1999). Moreover, it was found that bacteria exert their effect on E. histolytica virulence through cell surface entities such as lectin that attach to specific carbohydrate domains. One such gene coding for a $35-\mathrm{kDa}$ lectin subunit of a heterodimeric Gal/GalNAc lectin molecule was found to be involved in promoting pathogenicity of the parasite, whereas the heavy chain subunit of $170 \mathrm{kDa}$ was involved in adherence and attachment to the bacteria (Bhattacharya et al., 1992, 1998; Ankri et al., 1998; PadillaVaca et al., 1999). Apart from virulence, incubation with intestinal bacterial flora was suggested to trigger encystations in this parasite, which may explain why E. histolytica axenic cultures are unable to encyst in vitro (Ehrenkaufer et al., 2007). E. histolytica also has a direct influence on the gut microbiota composition (Verma et al., 2012). The presence of enteropathogenic bacteria (Paniagua et al., 2007) or the presence of Prevotella copri (Gilchrist et al., 2016), a normal component of the gut microbiota, has been correlated with E. histolytica infection. In contrast, the presence of Clostridia segmented filamentous bacteria is harmful to the parasite (Burgess et al., 2014).

\section{REFERENCES}

Aiken, C. T., Kaake, R. M., Wang, X., and Huang, L. (2011). Oxidative stressmediated regulation of proteasome complexes. Mol. Cell. Proteomics 10, R110 006924. doi: 10.1074/mcp.R110.006924

Akbar, M. A., Chatterjee, N. S., Sen, P., Debnath, A., Pal, A., Bera, T., et al. (2004). Genes induced by a high-oxygen environment in Entamoeba histolytica. Mol. Biochem. Parasitol. 133, 187-196. doi: 10.1016/j.molbiopara.2003.10.006

\section{CONCLUDING REMARKS}

Appropriate adaptation to stress is essential for E. histolytica's survival in harsh environments. In this review, we have shown that the parasite has developed multiple mechanisms regulated at the transcriptomics or at the post-transcriptomics level that allow an adequate response to a specific stress. While some features of the response of E. histolytica to stress are stress specific, some features such as the extensive reorganization of gene expression and expression of Hsps or antioxidant proteins such as thioredoxin are shared among different stresses. For years, studies about E. histolytica's response to stresses have almost exclusively focused on the instant response of the parasite to acute stresses, but its ability to adapt to these stresses has not been sufficiently considered. Recent reports are illustrating the exceptional ability of this parasite to adapt to various stresses like GS, NS, and the role of DPD and NAOD proteins in the mechanism of adaptation (Baumel-Alterzon et al., 2013; Shahi et al., 2016b). We believe that strategies that counteract the protective effect of these proteins may be valuable in the struggle against this parasite. The identification of new targets for antiamebic therapeutics will also beneficiate from a better integration of omics data available in the literature and of the ones to come. Multi-omic processing and combination of these data is a general challenge (Palsson and Zengler, 2010) that can only be overcome by training competent people to perform this task. Finally, it is essential not to neglect the procedures downstream to omics analysis of $E$. histolytica by improving current animal models of amoebiasis (Tsutsumi and Shibayama, 2006). This will enable us to reproduce the clinical manifestations observed in the human host in a better way. Moreover, the tools to knock out/downregulate gene expression can be enhanced (Morgado et al., 2016) by adapting CRISPR/Cas9 system to E. histolytica (Cui and $\mathrm{Yu}, 2016$ ).

\section{AUTHOR CONTRIBUTIONS}

All authors listed, have made substantial, direct and intellectual contribution to the work, and approved it for publication.

\section{FUNDING}

This study was supported by the Israel Ministry of Health within the framework ERA-NET Infect-ERA (031L0004) (AMOEBAC project) and grants from the Israel Science Foundation (ISF) (260/16) and U.S.-Israel Binational Science Foundation (BSF) (2015211).

Ali, I. K., Haque, R., Siddique, A., Kabir, M., Sherman, N. E., Gray, S, A., et al. (2012). Proteomic analysis of the cyst stage of Entamoeba histolytica. PLoS Negl. Trop. Dis. 6:e1643. doi: 10.1371/journal.pntd. 0001643

Ali, V., Shigeta, Y., Tokumoto, U., Takahashi, Y., and Nozaki, T. (2004). An intestinal parasitic protist, Entamoeba histolytica, possesses a non-redundant nitrogen fixation-like system for iron-sulfur cluster assembly under anaerobic conditions. J. Biol. Chem. 279, 16863-16874. doi: 10.1074/jbc.M313314200 
Ankri, S., Stolarsky, T., and Mirelman, D. (1998). Antisense inhibition of expression of cysteine proteinases does not affect Entamoeba histolytica cytopathic or haemolytic activity but inhibits phagocytosis. Mol. Microbiol. 28, 777-785. doi: 10.1046/j.1365-2958.1998.00837.x

Apel, K., and Hirt, H. (2004). Reactive oxygen species: metabolism, oxidative stress, and signal transduction. Annu. Rev. Plant Biol. 55, 373-399. doi: 10.1146/annurev.arplant.55.031903.141701

Baumel-Alterzon, S., and Ankri, S. (2014). Entamoeba histolytica adaptation to glucose starvation: a matter of life and death. Curr. Opin. Microbiol. 20, 139-145. doi: 10.1016/j.mib.2014.06.005

Baumel-Alterzon, S., Weber, C., Guillen, N., and Ankri, S. (2013). Identification of dihydropyrimidine dehydrogenase as a virulence factor essential for the survival of Entamoeba histolytica in glucose-poor environments. Cell. Microbiol. 15, 130-144. doi: 10.1111/cmi.12036

Beaulande, M., Tarbouriech, N., and Hartlein, M. (1998). Human cytosolic asparaginyl-tRNA synthetase: cDNA sequence, functional expression in Escherichia coli and characterization as human autoantigen. Nucleic Acids Res. 26, 521-524. doi: 10.1093/nar/26.2.521

Begum, S., Quach, J., and Chadee, K. (2015). Immune evasion mechanisms of Entamoeba histolytica: progression to disease. Front. Microbiol. 6:1394. doi: 10.3389/fmicb.2015.01394

Beinert, H., Holm, R. H., and Munck, E. (1997). Iron-sulfur clusters: nature's modular, multipurpose structures. Science 277, 653-659. doi: $10.1126 /$ science.277.5326.653

Bhattacharya, A., Anand, M. T., Paul, J., Yadav, N., and Bhattacharya, S. (1998). Molecular changes in Entamoeba histolytica in response to bacteria. J. Eukaryot Microbiol. 45, 28S-33S. doi: 10.1111/j.1550-7408.1998.tb04521.x

Bhattacharya, A., Ghildyal, R., Prasad, J., Bhattacharya, S., and Diamond, L. S. (1992). Modulation of a surface antigen of Entamoeba histolytica in response to bacteria. Infect. Immun. 60, 1711-1713.

Biagini, G. A., Park, J. H., Lloyd, D., and Edwards, M. R. (2001). The antioxidant potential of pyruvate in the amitochondriate diplomonads Giardia intestinalis and Hexamita inflata. Microbiology 147, 3359-3365. doi: 10.1099/00221287-147-12-3359

Biller, L., Davis, P. H., Tillack, M., Matthiesen, J., Lotter, H., Stanley, S. L. Jr., et al. (2010). Differences in the transcriptome signatures of two genetically related Entamoeba histolytica cell lines derived from the same isolate with different pathogenic properties. BMC Genomics 11:63. doi: 10.1186/14712164-11-63

Biller, L., Matthiesen, J., Kuhne, V., Lotter, H., Handal, G., Nozaki, T., et al. (2014). The cell surface proteome of Entamoeba histolytica. Mol. Cell. Proteomics 13, 132-144. doi: 10.1074/mcp.M113.031393

Blondal, T., Hjorleifsdottir, S., Aevarsson, A., Fridjonsson, O. H., Skirnisdottir, S., Wheat, J. O., et al. (2005). Characterization of a 5'-polynucleotide kinase/3'phosphatase from bacteriophage RM378. J. Biol. Chem. 280, 5188-5194. doi: $10.1074 /$ jbc.M409211200

Bracha, R., and Mirelman, D. (1984). Virulence of Entamoeba histolytica trophozoites. effects of bacteria, microaerobic conditions, and metronidazole. J. Exp. Med. 160, 353-368. doi: 10.1084/jem.160.2.353

Bracha, R., Kobiler, D., and Mirelman, D. (1982). Attachment and ingestion of bacteria by trophozoites of Entamoeba histolytica. Infect. Immun. 36, 396-406.

Bruchhaus, I., and Tannich, E. (1994). Induction of the iron-containing superoxide dismutase in Entamoeba histolytica by a superoxide aniongenerating system or by iron chelation. Mol. Biochem. Parasitol. 67, 281-288. doi: 10.1016/0166-6851(94)00143-X

Burgess, S. L., Buonomo, E., Carey, M., Cowardin, C., Naylor, C., Noor, Z., et al. (2014). Bone marrow dendritic cells from mice with an altered microbiota provide interleukin 17A-dependent protection against Entamoeba histolytica colitis. MBio 5:e01817. doi: 10.1128/mBio.01817-14

Chang, C. L., Marra, G., Chauhan, D. P., Ha, H. T., Chang, D. K., Ricciardiello, L., et al. (2002). Oxidative stress inactivates the human DNA mismatch repair system. Am. J. Physiol. Cell Physiol. 283, C148-C154. doi: 10.1152/ajpcell.00422.2001

Chang, C., and Lin, H. (2016). Dysbiosis in gastrointestinal disorders. Best Pract. Res. Clin. Gastroenterol. 30, 3-15. doi: 10.1016/j.bpg.2016.02.001

Cui, Y., and Yu, L. (2016). Application of the CRISPR/Cas9 gene editing technique to research on functional genomes of parasites. Parasitol. Int. 65, 641-644. doi: $10.1016 /$ j.parint.2016.08.011
Cummings, J. H., and Macfarlane, G. T. (1997). Role of intestinal bacteria in nutrient metabolism. J. Parenter. Enteral Nutr. 21, 357-365. doi: $10.1177 / 0148607197021006357$

Darling, N. J., and Cook, S. J. (2014). The role of MAPK signalling pathways in the response to endoplasmic reticulum stress. Biochim. Biophys. Acta 1843, 2150-2163. doi: 10.1016/j.bbamcr.2014. 01.009

Davis, P. H., Zhang, X., Guo, J., Townsend, R. R., and Stanley, S. L. Jr. (2006). Comparative proteomic analysis of two Entamoeba histolytica strains with different virulence phenotypes identifies peroxiredoxin as an important component of amoebic virulence. Mol. Microbiol. 61, 1523-1532. doi: 10.1111/j.1365-2958.2006.05344.x

De Nadal, E., Ammerer, G., and Posas, F. (2011). Controlling gene expression in response to stress. Nat. Rev. Genet. 12, 833-845. doi: 10.1038/nrg3055

Debnath, A., Parsonage, D., Andrade, R. M., He, C., Cobo, E. R., Hirata, K., et al. (2012). A high-throughput drug screen for Entamoeba histolytica identifies a new lead and target. Nat. Med. 18, 956-960. doi: 10.1038/nm.2758

Ehrenkaufer, G. M., Haque, R., Hackney, J. A., Eichinger, D. J., and Singh, U. (2007). Identification of developmentally regulated genes in Entamoeba histolytica: insights into mechanisms of stage conversion in a protozoan parasite. Cell. Microbiol. 9, 1426-1444. doi: 10.1111/j.1462-5822.2006.00882.x

Espinosa, A., Perdrizet, G., Paz, Y. M. C. G., Lanfranchi, R., and Phay, M. (2009). Effects of iron depletion on Entamoeba histolytica alcohol dehydrogenase 2 (EhADH2) and trophozoite growth: implications for antiamoebic therapy. J. Antimicrob. Chemother. 63, 675-678. doi: 10.1093/jac/dkp015

Fisher, O., Siman-Tov, R., and Ankri, S. (2006). Pleiotropic phenotype in Entamoeba histolytica overexpressing DNA methyltransferase (Ehmeth). Mol. Biochem. Parasitol. 147, 48-54. doi: 10.1016/j.molbiopara.2006.01.007

Forrester, M. T., Thompson, J. W., Foster, M. W., Nogueira, L., Moseley, M. A., and Stamler, J. S. (2009). Proteomic analysis of S-nitrosylation and denitrosylation by resin-assisted capture. Nat. Biotechnol. 27, 557-559. doi: 10.1038/nbt.1545

Gilchrist, C. A., Houpt, E., Trapaidze, N., Fei, Z., Crasta, O., Asgharpour, A., et al. (2006). Impact of intestinal colonization and invasion on the Entamoeba histolytica transcriptome. Mol. Biochem. Parasitol. 147, 163-176. doi: 10.1016/j.molbiopara.2006.02.007

Gilchrist, C. A., Moore, E. S., Zhang, Y., Bousquet, C. B., Lannigan, J. A., Mann, B. J., et al. (2010). Regulation of virulence of Entamoeba histolytica by the URE3-BP transcription factor. MBio 1:e00057-10. doi: 10.1128/mBio.00057-10

Gilchrist, C. A., Petri, S. E., Schneider, B. N., Reichman, D. J., Jiang, N., Begum, S., et al. (2016). Role of the gut microbiota of children in diarrhea due to the protozoan parasite Entamoeba histolytica. J. Infect. Dis. 213, 1579-1585. doi: 10.1093/infdis/jiv772

Girjes, A. A., Hobson, K., Chen, P., and Lavin, M. F. (1995). Cloning and characterization of cDNA encoding a human arginyl-tRNA synthetase. Gene 164, 347-350. doi: 10.1016/0378-1119(95)00502-W

Gould, N., Doulias, P. T., Tenopoulou, M., Raju, K., and Ischiropoulos, H. (2013). Regulation of protein function and signaling by reversible cysteine S-nitrosylation. J. Biol. Chem. 288, 26473-26479. doi: 10.1074/jbc.R113.460261 Hendrick, H. M., Welter, B. H., Hapstack, M. A., Sykes, S. E., Sullivan, W. J. Jr., and Temesvari, L. A. (2016). Phosphorylation of eukaryotic initiation factor-2alpha during stress and encystation in entamoeba species. PLoS Pathog. 12:e1006085. doi: 10.1371/journal.ppat.1006085

Hernandez-Cuevas, N. A., Weber, C., Hon, C. C., and Guillen, N. (2014). Gene expression profiling in Entamoeba histolytica identifies key components in iron uptake and metabolism. PLoS ONE 9:e107102. doi: 10.1371/journal.pone. 0107102

Hertz, R., Ben Lulu, S., Shahi, P., Trebicz-Geffen, M., Benhar, M., and Ankri, S. (2014a). Proteomic identification of S-nitrosylated proteins in the parasite Entamoeba histolytica by resin-assisted capture: insights into the regulation of the Gal/GalNAc lectin by nitric oxide. PLoS ONE 9:e91518. doi: 10.1371/journal.pone.0091518

Hertz, R., Tovy, A., Kirschenbaum, M., Geffen, M., Nozaki, T., Adir, N., et al. (2014b). The Entamoeba histolytica Dnmt2 homolog (Ehmeth) confers resistance to nitrosative stress. Eukaryotic Cell 13, 494-503. doi: 10.1128/EC.00031-14

Hess, D. T., Matsumoto, A., Kim, S. O., Marshall, H. E., and Stamler, J. S. (2005). Protein S-nitrosylation: purview and parameters. Nat. Rev. Mol. Cell Biol. 6, 150-166. doi: $10.1038 / \mathrm{nrm} 1569$ 
Hirayama, A., Kami, K., Sugimoto, M., Sugawara, M., Toki, N., Onozuka, H., et al. (2009). Quantitative metabolome profiling of colon and stomach cancer microenvironment by capillary electrophoresis time-of-flight mass spectrometry. Cancer Res. 69, 4918-4925. doi: 10.1158/0008-5472.CAN-08-4806

Husain, A., Jeelani, G., Sato, D., and Nozaki, T. (2011). Global analysis of gene expression in response to L-Cysteine deprivation in the anaerobic protozoan parasite Entamoeba histolytica. BMC Genomics 12:275. doi: 10.1186/1471-2164-12-275

Husain, A., Sato, D., Jeelani, G., Mi-Ichi, F., Ali, V., Suematsu, M., et al. (2010). Metabolome analysis revealed increase in S-methylcysteine and phosphatidylisopropanolamine synthesis upon L-cysteine deprivation in the anaerobic protozoan parasite Entamoeba histolytica. J. Biol. Chem. 285, 39160-39170. doi: 10.1074/jbc.M110.167304

Husain, A., Sato, D., Jeelani, G., Soga, T., and Nozaki, T. (2012). Dramatic increase in glycerol biosynthesis upon oxidative stress in the anaerobic protozoan parasite Entamoeba histolytica. PLoS Negl. Trop. Dis. 6:e1831. doi: 10.1371/journal.pntd.0001831

Hussain, S., Ali, V., Jeelani, G., and Nozaki, T. (2009). Isoform-dependent feedback regulation of serine $\mathrm{O}$-acetyltransferase isoenzymes involved in L-cysteine biosynthesis of Entamoeba histolytica. Mol. Biochem. Parasitol. 163, 39-47. doi: 10.1016/j.molbiopara.2008.09.006

Imlay, J. A. (2003). Pathways of oxidative damage. Annu. Rev. Microbiol. 57, 395-418. doi: 10.1146/annurev.micro.57.030502.090938

Ishikane, M., Arima, Y., Kanayama, A., Takahashi, T., Yamagishi, T., Yahata, Y., et al. (2016). Epidemiology of domestically acquired amebiasis in Japan, 2000-2013. Am. J. Trop. Med. Hyg. 94, 1008-1014. doi: 10.4269/ajtmh.15-0560

Jandhyala, S. M., Talukdar, R., Subramanyam, C., Vuyyuru, H., Sasikala, M., and Nageshwar Reddy, D. (2015). Role of the normal gut microbiota. World J. Gastroenterol. 21, 8787-8803. doi: 10.3748/wjg.v21.i29.8787

Jeelani, G., and Nozaki, T. (2014). Metabolomic analysis of entamoeba: applications and implications. Curr. Opin. Microbiol. 20, 118-124. doi: $10.1016 /$ j.mib.2014.05.016

Jeelani, G., and Nozaki, T. (2016). Entamoeba thiol-based redox metabolism: a potential target for drug development. Mol. Biochem. Parasitol. 206, 39-45. doi: 10.1016/j.molbiopara.2016.01.004

Jeelani, G., Husain, A., Sato, D., Ali, V., Suematsu, M., Soga, T., et al. (2010). Two atypical L-cysteine-regulated NADPH-dependent oxidoreductases involved in redox maintenance, L-cystine and iron reduction, and metronidazole activation in the enteric protozoan Entamoeba histolytica. J. Biol. Chem. 285, 26889-26899. doi: 10.1074/jbc.M110.106310

Jeelani, G., Sato, D., Soga, T., Watanabe, H., and Nozaki, T. (2014). Mass spectrometric analysis of L-cysteine metabolism: physiological role and fate of L-cysteine in the enteric protozoan parasite Entamoeba histolytica. MBio 5, e01995. doi: 10.1128/mBio.01995-14

Jiang, H. Y., and Wek, R. C. (2005). Phosphorylation of the alpha-subunit of the eukaryotic initiation factor-2 (eIF2alpha) reduces protein synthesis and enhances apoptosis in response to proteasome inhibition. J. Biol. Chem. 280, 14189-14202. doi: 10.1074/jbc.M413660200

Kaul, G., and Thippeswamy, H. (2011). Role of heat shock proteins in diseases and their therapeutic potential. Indian J. Microbiol. 51, 124-131. doi: 10.1007/s12088-011-0147-9

Kellett, G. L., Brot-Laroche, E., Mace, O. J., and Leturque, A. (2008). Sugar absorption in the intestine: the role of GLUT2. Annu. Rev. Nutr. 28, 35-54. doi: 10.1146/annurev.nutr.28.061807.155518

Kohr, M. J., Sun, J., Aponte, A., Wang, G., Gucek, M., Murphy, E., et al. (2011). Simultaneous measurement of protein oxidation and S-nitrosylation during preconditioning and ischemia/reperfusion injury with resinassisted capture. Circ. Res. 108, 418-426. doi: 10.1161/CIRCRESAHA.110. 232173

Kolios, G., Valatas, V., and Ward, S. G. (2004). Nitric oxide in inflammatory bowel disease: a universal messenger in an unsolved puzzle. Immunology 113, 427-437. doi: 10.1111/j.1365-2567.2004.01984.x

Krauth-Siegel, R. L., and Leroux, A. E. (2012). Low-molecular-mass antioxidants in parasites. Antioxid. Redox Signal. 17, 583-607. doi: 10.1089/ars.2011.4392

Lee, J., Park, S. J., and Yong, T. S. (2008). Effect of iron on adherence and cytotoxicity of Entamoeba histolytica to $\mathrm{CHO}$ cell monolayers. Korean J. Parasitol. 46, 37-40. doi: 10.3347/kjp.2008.46.1.37
Leitsch, D., Kolarich, D., Wilson, I. B. H., Altmann, F., and Duchene, M. (2007). Nitroimidazole action in Entamoeba histolytica: a central role for thioredoxin reductase. PLoS Biol. 5, 1820-1834. doi: 10.1371/journal.pbio.0050211

López-Camarillo, C., Zamorano, A., Hernández De La Cruz, O., López Rosas, I., and Marchat, L. (2009). Genomics approaches in the understanding of Entamoeba histolytica virulence and gene expression regulation. Afr. J. Biotechnol. 8, 1363-1369.

Lopez-Maury, L., Marguerat, S., and Bahler, J. (2008). Tuning gene expression to changing environments: from rapid responses to evolutionary adaptation. Nat. Rev. Genet. 9, 583-593. doi: 10.1038/nrg2398

Lopez-Soto, F., Gonzalez-Robles, A., Salazar-Villatoro, L., Leon-Sicairos, N., PinaVazquez, C., Salazar, E. P., et al. (2009). Entamoeba histolytica uses ferritin as an iron source and internalises this protein by means of clathrin-coated vesicles. Int. J. Parasitol. 39, 417-426. doi: 10.1016/j.ijpara.2008.08.010

Luna-Nacar, M., Navarrete-Perea, J., Moguel, B., Bobes, R. J., Laclette, J. P., and Carrero, J. C. (2016). Proteomic study of Entamoeba histolytica trophozoites, cysts, and cyst-like structures. PLoS ONE11:e0156018. doi: 10.1371/journal.pone. 0156018

Maralikova, B., Ali, V., Nakada-Tsukui, K., Nozaki, T., Van Der Giezen, M., Henze, K., et al. (2010). Bacterial-type oxygen detoxification and iron-sulfur cluster assembly in amoebal relict mitochondria. Cell. Microbiol. 12, 331-342. doi: 10.1111/j.1462-5822.2009.01397.x

Marie, C., and Petri, W. A. Jr. (2013). Amoebic dysentery. BMJ Clin. Evid. 2013:0918.

Mirelman, D. (1987). Ameba-bacterium relationship in amebiasis. Microbiol. Rev. $51,272-284$.

Moonah, S. N., Jiang, N. M., and Petri, W. A. Jr. (2013). Host immune response to intestinal amebiasis. PLoS Pathog 9:e1003489. doi: 10.1371/journal.ppat.1003489

Morgado, P., Manna, D., and Singh, U. (2016). Recent advances in entamoeba biology: RNA interference, drug discovery, and gut microbiome. F1000Res 5:2578. doi: 10.12688/f1000research.9241.1

Mortimer, L., and Chadee, K. (2010). The immunopathogenesis of Entamoeba histolytica. Exp. Parasitol. 126, 366-380. doi: 10.1016/j.exppara.2010.03.005

Nakada-Tsukui, K., and Nozaki, T. (2016). Immune Response of Amebiasis and Immune Evasion by Entamoeba histolytica. Front. Immunol. 7:175. doi: 10.3389/fimmu.2016.00175

Nath, J., Ghosh, S. K., Singha, B., and Paul, J. (2015). Molecular epidemiology of amoebiasis: a cross-sectional study among North east Indian population. PLoS Negl. Trop. Dis. 9:e0004225. doi: 10.1371/journal.pntd.0004225

Nguyen, C., Kasinathan, G., Leal-Cortijo, I., Musso-Buendia, A., Kaiser, M., Brun, R., et al. (2005). Deoxyuridine triphosphate nucleotidohydrolase as a potential antiparasitic drug target. J. Med. Chem. 48, 5942-5954. doi: 10.1021/jm050111e

Nicholls, C., Li, H., and Liu, J. P. (2012). GAPDH: a common enzyme with uncommon functions. Clin. Exp. Pharmacol. Physiol. 39, 674-679. doi: 10.1111/j.1440-1681.2011.05599.x

Olivos-Garcia, A., Saavedra, E., Nequiz, M., Santos, F., Luis-Garcia, E. R., Gudino, M., et al. (2016). The oxygen reduction pathway and heat shock stress response are both required for Entamoeba histolytica pathogenicity. Curr. Genet. 62, 295-300. doi: 10.1007/s00294-015-0543-5

Padilla-Vaca, F., Ankri, S., Bracha, R., Koole, L. A., and Mirelman, D. (1999). Down regulation of Entamoeba histolytica virulence by monoxenic cultivation with Escherichia coli $\mathrm{O} 55$ is related to a decrease in expression of the light (35-kilodalton) subunit of the Gal/GalNAc lectin. Infect. Immun. 67, 2096-2102.

Palsson, B., and Zengler, K. (2010). The challenges of integrating multi-omic data sets. Nat. Chem. Biol. 6, 787-789. doi: 10.1038/nchembio.462

Paniagua, G. L., Monroy, E., Garcia-Gonzalez, O., Alonso, J., Negrete, E., and Vaca, S. (2007). Two or more enteropathogens are associated with diarrhoea in Mexican children. Ann. Clin. Microbiol. Antimicrob. 6:17. doi: 10.1186/1476-0711-6-17

Park, S. J., Lee, S. M., Lee, J., and Yong, T. S. (2001). Differential gene expression by iron-limitation in Entamoeba histolytica. Mol. Biochem. Parasitol. 114, 257-260. doi: 10.1016/S0166-6851(01)00264-X

Pearson, R. J., Morf, L., and Singh, U. (2013). Regulation of $\mathrm{H} 2 \mathrm{O} 2$ stress-responsive genes through a novel transcription factor in the protozoan pathogen Entamoeba histolytica. J. Biol. Chem. 288, 4462-4474. doi: $10.1074 /$ jbc.M112.423467 
Perez-Morales, D., and Espinoza, B. (2015). The role of small heat shock proteins in parasites. Cell Stress Chaperones 20, 767-780. doi: 10.1007/s12192-015-0607-y

Perez-Victoria, J. M., Parodi-Talice, A., Torres, C., Gamarro, F., and Castanys, S. (2001). ABC transporters in the protozoan parasite Leishmania. Int. Microbiol. 4, 159-166. doi: 10.1007/s10123-001-0031-2

Pineda, E., and Perdomo, D. (2017). Entamoeba histolytica under oxidative stress: what countermeasure mechanisms are in place? Cells 6:44. doi: 10.3390/cells6040044

Pye, V. E., Tingey, A. P., Robson, R. L., and Moody, P. C. (2004). The structure and mechanism of serine acetyltransferase from Escherichia coli. J. Biol. Chem. 279, 40729-40736. doi: 10.1074/jbc.M403751200

Rafferty, S. P., and Dayer, G. (2015). Heme proteins of Giardia intestinalis. Exp. Parasitol. 159, 13-23. doi: 10.1016/j.exppara.2015.08.001

Rastew, E., Vicente, J. B., and Singh, U. (2012). Oxidative stress resistance genes contribute to the pathogenic potential of the anaerobic protozoan parasite, Entamoeba histolytica. Int. J. Parasitol. 42, 1007-1015. doi: 10.1016/j.ijpara.2012.08.006

Salles, J. M., Salles, M. J., Moraes, L. A., and Silva, M. C. (2007). Invasive amebiasis: an update on diagnosis and management. Expert Rev. Anti Infect. Ther. 5, 893-901. doi: 10.1586/14787210.5.5.893

Santi-Rocca, J., Smith, S., Weber, C., Pineda, E., Hon, C. C., Saavedra, E., et al. (2012). Endoplasmic reticulum stress-sensing mechanism is activated in Entamoeba histolytica upon treatment with nitric oxide. PLoS ONE 7:e31777. doi: 10.1371/journal.pone.0031777

Santos, F., Nequiz, M., Hernandez-Cuevas, N. A., Hernandez, K., Pineda, E., Encalada, R., et al. (2015). Maintenance of intracellular hypoxia and adequate heat shock response are essential requirements for pathogenicity and virulence of Entamoeba histolytica. Cell. Microbiol. 17, 1037-1051. doi: $10.1111 / \mathrm{cmi} .12419$

Sen, A., Chatterjee, N. S., Akbar, M. A., Nandi, N., and Das, P. (2007). The 29-kilodalton thiol-dependent peroxidase of Entamoeba histolytica is a factor involved in pathogenesis and survival of the parasite during oxidative stress. Eukaryotic Cell 6, 664-673. doi: 10.1128/EC.00308-06

Shacter, E. (2000). Quantification and significance of protein oxidation in biological samples. Drug Metab. Rev. 32, 307-326. doi: 10.1081/DMR-100102336

Shahi, P., Trebicz-Geffen, M., Nagaraja, S., Alterzon-Baumel, S., Hertz, R., Methling, K., et al. (2016a). Proteomic identification of oxidized proteins in Entamoeba histolytica by resin-assisted capture: insights into the role of arginase in resistance to oxidative stress. PLoS Negl. Trop. Dis. 10:e0004340. doi: 10.1371/journal.pntd.0004340

Shahi, P., Trebicz-Geffen, M., Nagaraja, S., Hertz, R., Alterzon-Baumel, S., Methling, K., et al. (2016b). N-acetyl ornithine deacetylase is a moonlighting protein and is involved in the adaptation of Entamoeba histolytica to nitrosative stress. Sci. Rep. 6:36323. doi: 10.1038/srep36323

Sharma, D. K., Bressler, K., Patel, H., Balasingam, N., and Thakor, N. (2016). Role of eukaryotic initiation factors during cellular stress and cancer progression. $J$. Nucleic Acids 2016:8235121. doi: 10.1155/2016/8235121

Siman-Tov, R., and Ankri, S. (2003). Nitric oxide inhibits cysteine proteinases and alcohol dehydrogenase 2 of Entamoeba histolytica. Parasitol. Res. 89, 146-149. doi: 10.1007/s00436-002-0716-2

Smith, K. T., and Workman, J. L. (2012). Chromatin proteins: key responders to stress. PLoS Biol. 10:e1001371. doi: 10.1371/journal.pbio.1001371

Sonnenburg, J. L., Angenent, L. T., and Gordon, J. I. (2004). Getting a grip on things: how do communities of bacterial symbionts become established in our intestine? Nat. Immunol. 5, 569-573. doi: 10.1038/ni1079

Tannich, E., Bruchhaus, I., Walter, R. D., and Horstmann, R. D. (1991). Pathogenic and nonpathogenic Entamoeba histolytica: identification and molecular cloning of an iron-containing superoxide dismutase. Mol. Biochem. Parasitol. 49, 61-71. doi: 10.1016/0166-6851(91)90130-X

Tazreiter, M., Leitsch, D., Hatzenbichler, E., Mair-Scorpio, G. E., Steinborn, R., Schreiber, M., et al. (2008). Entamoeba histolytica: response of the parasite to metronidazole challenge on the levels of mRNA and protein expression. Exp. Parasitol. 120, 403-410. doi: 10.1016/j.exppara.2008. 09.011

Tekwani, B. L., and Mehlotra, R. K. (1999). Molecular basis of defence against oxidative stress in Entamoeba histolytica and Giardia lamblia. Microbes Infect. 1, 385-394. doi: 10.1016/S1286-4579(99)80055-0
Testa, F., Mastronicola, D., Cabelli, D. E., Bordi, E., Pucillo, L. P., Sarti, P., et al. (2011). The superoxide reductase from the early diverging eukaryote Giardia intestinalis. Free Radic. Biol. Med. 51, 1567-1574. doi: 10.1016/j.freeradbiomed.2011.07.017

Thibeaux, R., Weber, C., Hon, C. C., Dillies, M. A., Ave, P., Coppee, J. Y., et al. (2013). Identification of the virulence landscape essential for Entamoeba histolytica invasion of the human colon. PLoS Pathog. 9:e1003824. doi: 10.1371/journal.ppat.1003824

Thomas, D. D., Ridnour, L. A., Isenberg, J. S., Flores-Santana, W., Switzer, C. H., Donzelli, S., et al. (2008). The chemical biology of nitric oxide: implications in cellular signaling. Free Radic. Biol. Med. 45, 18-31. doi: 10.1016/j.freeradbiomed.2008.03.020

Thursby, E., and Juge, N. (2017). Introduction to the human gut microbiota. Biochem. J. 474, 1823-1836. doi: 10.1042/BCJ20160510

Tovy, A., Hertz, R., Siman-Tov, R., Syan, S., Faust, D., Guillen, N., et al. (2011). Glucose starvation boosts Entamoeba histolytica virulence. PLoS Negl. Trop. Dis. 5:e1247. doi: 10.1371/journal.pntd.0001247

Tovy, A., Siman Tov, R., Gaentzsch, R., Helm, M., and Ankri, S. (2010). A new nuclear function of the Entamoeba histolytica glycolytic enzyme enolase: the metabolic regulation of cytosine-5 methyltransferase 2 (Dnmt2) activity. PLoS Pathog. 6:e1000775. doi: 10.1371/journal.ppat.1000775

Trebicz-Geffen, M., Shahi, P., Nagaraja, S., Vanunu, S., Manor, S., Avrahami, A., et al. (2017). Identification of S-nitrosylated (SNO) proteins in Entamoeba histolytica adapted to nitrosative stress: insights into the role of SNO actin and in vitro virulence. Front. Cell. Infect. Microbiol. 7:192. doi: $10.3389 /$ fcimb.2017.00192

Tsutsumi, V., and Shibayama, M. (2006). Experimental amebiasis: a selected review of some in vivo models. Arch. Med. Res. 37, 210-220. doi: 10.1016/j.arcmed.2005.09.011

Ujang, J. A., Kwan, S. H., Ismail, M. N., Lim, B. H., Noordin, R., and Othman, N. (2016). Proteome analysis of excretory-secretory proteins of Entamoeba histolytica HM1:IMSS via LC-ESI-MS/MS and LC-MALDI-TOF/TOF. Clin. Proteomics 13, 33. doi: 10.1186/s12014-016-9135-8

Verma, A. K., Verma, R., Ahuja, V., and Paul, J. (2012). Real-time analysis of gut flora in Entamoeba histolytica infected patients of Northern India. BMC Microbiol. 12:183. doi: 10.1186/1471-2180-12-183

Vermeiren, J., Van De Wiele, T., Verstraete, W., Boeckx, P., and Boon, N. (2009). Nitric oxide production by the human intestinal microbiota by dissimilatory nitrate reduction to ammonium. J. Biomed. Biotechnol. 2009:284718. doi: 10.1155/2009/284718

Vicente, J. B., Ehrenkaufer, G. M., Saraiva, L. M., Teixeira, M., and Singh, U. (2009). Entamoeba histolytica modulates a complex repertoire of novel genes in response to oxidative and nitrosative stresses: implications for amebic pathogenesis. Cell. Microbiol. 11, 51-69. doi: 10.1111/j.1462-5822.2008.01236.x Voisine, C., Craig, E. A., Zufall, N., Von Ahsen, O., Pfanner, N., and Voos, W. (1999). The protein import motor of mitochondria: unfolding and trapping of preproteins are distinct and separable functions of matrix Hsp70. Cell 97, 565-574. doi: 10.1016/S0092-8674(00)80768-0

Vonlaufen, N., Kanzok, S. M., Wek, R. C., and Sullivan, W. J. Jr. (2008). Stress response pathways in protozoan parasites. Cell. Microbiol. 10, 2387-2399. doi: $10.1111 / \mathrm{j} .1462-5822.2008 .01210 . \mathrm{x}$

Walter, P., and Ron, D. (2011). The unfolded protein response: from stress pathway to homeostatic regulation. Science 334, 1081-1086. doi: $10.1126 /$ science. 1209038

Wandersman, C., and Delepelaire, P. (2004). Bacterial iron sources: from siderophores to hemophores. Annu. Rev. Microbiol. 58, 611-647. doi: 10.1146/annurev.micro.58.030603.123811

Weber, C., Guigon, G., Bouchier, C., Frangeul, L., Moreira, S., Sismeiro, O. et al. (2006). Stress by heat shock induces massive down regulation of genes and allows differential allelic expression of the Gal/GalNAc lectin in Entamoeba histolytica. Eukaryotic Cell 5, 871-875. doi: 10.1128/EC.5.5.871-87 5.2006

Weber, C., Marchat, L. A., Guillen, N., and Lopez-Camarillo, C. (2009). Effects of DNA damage induced by UV irradiation on gene expression in the protozoan parasite Entamoeba histolytica. Mol. Biochem. Parasitol. 164, 165-169. doi: 10.1016/j.molbiopara.2008.12.005

Wu, W. S., Tsai, R. K., Chang, C. H., Wang, S., Wu, J. R., and Chang, Y. X. (2006). Reactive oxygen species mediated sustained activation of protein kinase $\mathrm{C}$ alpha 
and extracellular signal-regulated kinase for migration of human hepatoma cell Hepg2. Mol. Cancer Res. 4, 747-758. doi: 10.1158/1541-7786.MCR-0 6-0096

Xu, J., Bjursell, M. K., Himrod, J., Deng, S., Carmichael, L. K., Chiang, H. C., et al. (2003). A genomic view of the human-Bacteroides thetaiotaomicron symbiosis. Science 299, 2074-2076. doi: 10.1126/science.1080029

Conflict of Interest Statement: The authors declare that the research was conducted in the absence of any commercial or financial relationships that could be construed as a potential conflict of interest.
The handling editor is currently editing co-organizing a Research Topic with one of the author SA, and confirms the absence of any other collaboration.

Copyright $(\odot 2018$ Nagaraja and Ankri. This is an open-access article distributed under the terms of the Creative Commons Attribution License (CC BY). The use, distribution or reproduction in other forums is permitted, provided the original author(s) and the copyright owner are credited and that the original publication in this journal is cited, in accordance with accepted academic practice. No use, distribution or reproduction is permitted which does not comply with these terms. 